ARTICLE

Received 19 Dec 2016 | Accepted 17 Jan 2017 | Published 6 Mar 2017

DOI: $10.1038 /$ ncomms14629 OPEN

\title{
A class of liquid anode for rechargeable batteries with ultralong cycle life
}

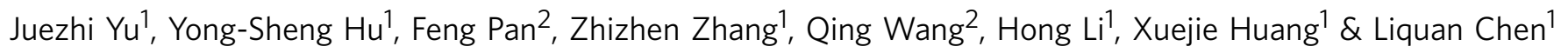

Low cost, highly efficient and safe devices for energy storage have long been desired in our society. Among these devices, electrochemical batteries with alkali metal anodes have attracted worldwide attention. However, the practical application of such systems is limited by dendrite formation and low cycling efficiency of alkali metals. Here we report a class of liquid anodes fabricated by dissolving sodium metal into a mixed solution of biphenyl and ethers. Such liquid anodes are highly safe and have a low redox potential of $0.09 \mathrm{~V}$ versus sodium, exhibiting a high conductivity of $1.2 \times 10^{-2} \mathrm{~S} \mathrm{~cm}^{-1}$. When coupled with polysulfides dissolved in dimethyl sulfoxide as the cathode, a battery is demonstrated to sustain over 3,500 cycles without measureable capacity loss at room temperature. This work provides a base for exploring a family of liquid anodes for rechargeable batteries that potentially meet the requirements for grid-scale electrical energy storage.

\footnotetext{
${ }^{1}$ Key Laboratory for Renewable Energy, Beijing Key Laboratory for New Energy Materials and Devices, Beijing National Laboratory for Condensed Matter Physics, Institute of Physics, Chinese Academy of Sciences, School of Physical Sciences, University of Chinese Academy of Sciences, Beijing 100190, China. ${ }^{2}$ Department of Materials Science and Engineering, National University of Singapore, Singapore 117576, Singapore. Correspondence and requests for materials should be addressed to Y.-S.H. (email: yshu@aphy.iphy.ac.cn).
} 
O ne of the 'Holy Grails' of rechargeable battery research is the successful application of alkali metals, such as lithium or sodium, as the anode to maximize the energy density utilizing their low negative potential and light weight ${ }^{1-7}$. However, the practical applications are hindered by the following formidable challenges. On the one hand, the alkali metals show poor cycling stability in organic liquid electrolytes because they are thermodynamically unstable with any kind of organic solvents. In addition, they tend to form dendrites during the deposition/stripping process, which increases the probability of internal short circuit, a well-known safety issue in real world applications ${ }^{8-12}$. On the other hand, even if the above-mentioned problems could be solved by replacing organic liquid electrolytes with solid electrolytes, other problems such as huge interfacial resistance between alkali metals and solid electrolytes could appear. As a result, molten or liquid alkali metals have been proposed, for example, in high-temperature sodium beta-alumina batteries, especially, the best-known sodium-sulfur $(\mathrm{Na}-\mathrm{S})$ and sodium-metal halide batteries. However, they need to be operated at a high temperature $\left(300-350{ }^{\circ} \mathrm{C}\right)$ to decrease the interfacial resistance and to obtain better wettability between the alkali metals and solid electrolytes ${ }^{13-17}$. The high operating temperature is unfavourable because it gives rise to high corrosion rate, increases costs of battery manufacture and maintenance, as well as induces safety hazards. Actually, a few safety incidents have occurred in the last few years, which underscores the fact that safety issues of such systems have not been completely resolved and will limit their wide-scale application.

Here we report a liquid anode to enable such batteries to be operated at room temperature or moderate temperature. The liquid anode can be prepared simply by dissolving alkali metals into a solution of aromatic hydrocarbon and ethers. In particular, the example of sodium dissolved in biphenyl and dimethoxyethane (denoted as Na-BP-DME) is taken to demonstrate the strategy because of the natural abundance and wide geographic distribution of sodium resources ${ }^{18,19}$. The obtained liquid anodes possess a low potential of $0.09 \mathrm{~V}$ versus $\mathrm{Na}$, a high conductivity of $1.2 \times 10^{-2} \mathrm{Scm}^{-1}$ at room temperature and are safer than $\mathrm{Na}$ metal anode. A rechargeable sodium beta-alumina battery is fabricated using the liquid anode and polysulfide cathode, presenting superior cycling performance at room temperature.

\section{Results}

Material synthesis and physical property. The alkali metals, such as $\mathrm{Li}$ and $\mathrm{Na}$, can react with some aromatic hydrocarbons in ether solvents to form a dark green alkali solution at room temperature. Such solutions have been known as radical anions and widely used as reducing agents in chemical synthesis since the $1930 \mathrm{~s}^{20-24}$, however, they were not explored as electrodes for rechargeable batteries. In the following, the Na-BP-DME system is taken as an example to demonstrate the feasibility of using alkali solution as anodes for rechargeable batteries. First, let us describe the physical properties. The solubility of sodium and biphenyl or biphenyl in dimethoxyethane is revealed to be up to $5 \mathrm{M}$ or $6 \mathrm{M}$, respectively, (Fig. 1a and Supplementary Fig. 1), which ensures a high volumetric energy density. Figure $1 \mathrm{~b}$ shows the electrochemical impedance spectra of Na-BP-DME solutions with different $\mathrm{Na}$ concentrations (the molar ratio between $\mathrm{Na}$ and biphenyl was fixed at 1:1). It can be seen that the resistance decreases rapidly with the increase of $\mathrm{Na}$ concentration. At the concentration of $1 \mathrm{M}$, the total conductivity was calculated to be $1.2 \times 10^{-2} \mathrm{~S} \mathrm{~cm}^{-1}$. To separate the electronic conductivity from the total conductivity, a special cell with a copper foil sandwiched between two Pt electrodes (Supplementary Fig. 2) was designed, which blocks $\mathrm{Na}^{+}$ion transport during the measurement. The electrochemical impedance of the $1 \mathrm{M}$ Na-BP-DME solutions was measured with an ion block cell and the spectrum is displayed in Fig. 1c, which help to calculate the electronic conductivity of $9.3 \times 10^{-3} \mathrm{~S} \mathrm{~cm}^{-1}$. Hence, the ionic conductivity is $2.7 \times 10^{-3} \mathrm{~S} \mathrm{~cm}^{-1}$. These values are sufficient for an electrode application.

The liquid electrode incorporated in the rechargeable battery has to be separated from the other electrode by a solid electrolyte. The wettability of this liquid electrode with the well-known Na- $\beta^{\prime \prime}-\mathrm{Al}_{2} \mathrm{O}_{3}$ solid electrolyte (BASE) was also checked. It can be seen that the Na-BP-DME liquid spreads over the entire surface of BASE at room temperature, suggesting a complete wetting of the surface with a contact angle of $\sim 0^{\circ}$ (Fig. 1d and Supplementary Videos 1 and 2). This wettability is much superior to that of any other alkali metals or their alloys, even at a temperature as high as $200^{\circ} \mathrm{C}$ (ref. 9). The superior stability of BASE in the Na-BP-DME solution was confirmed by the X-ray diffraction analysis (Supplementary Fig. 3).

Electrochemical performance. To determine the redox potential of the Na-BP-DME liquid solution, a Na-BP-DME|BASE|Na cell was fabricated. The open circuit voltage curve of the cell is presented in Fig. $2 \mathrm{a}$ and shows a redox potential of $0.09 \mathrm{~V}$ versus $\mathrm{Na}$, which is very close to the redox potential of $\mathrm{Na}$ metal, making this liquid suitable as an anode in rechargeable batteries. This low potential is also beneficial to maximize the energy density of a battery. The electrochemically reversible $\mathrm{Na}$ removal/uptake from this liquid solution was also demonstrated in a symmetric Na-BP-DME|BASE|Na-BP-DME cell and the corresponding electrochemical reactions at the cathode and anode are shown as equation (1).

The concentration of both electrodes was $1 \mathrm{M}$. The charge/ discharge capacity was fixed at $5 \mathrm{mAh}$ for a $0.43 \mathrm{ml}$ liquid cathode and anode, corresponding to $0.5 \mathrm{~mol} \mathrm{Na}$ removal/uptake per $1 \mathrm{~mol} \mathrm{Na-BP-DME}$ (named as $0.5 \mathrm{Na}-\mathrm{BP}-\mathrm{DME}$ and $1.5 \mathrm{Na}-\mathrm{BP}$ $\mathrm{DME}$, respectively). Figure $2 \mathrm{~b}$ indicates that this process is highly reversible. From this result, Na-BP-DME elecrtode can be charged/discharged between 0.5Na-BP-DME and 1.5Na-BP-DME (note that the conductivities of 0.5 Na-BP-DME and 1.5Na-BP-DME liquid solutions remain as high as $5.8 \times$ $10^{-3} \mathrm{~S} \mathrm{~cm}^{-1}$ and $1.4 \times 10^{-2} \mathrm{~S} \mathrm{~cm}^{-1}$, respectively, (Supplementary Fig. 4 and Supplementary Table 1)).

Based on these unique characteristics, we are able to construct a rechargeable battery using this liquid anode. Here we selected the liquid sulfur-based cathode to demonstrate the practical application of room temperature sodium beta-alumina batteries. The liquid cathode was prepared by dissolving $\mathrm{S}$ and $\mathrm{Na}_{2} \mathrm{~S}$ with a molar ratio of 7:1 into dimethyl sulfoxide (DMSO) solvent. The concentration of $\mathrm{Na}_{2} \mathrm{~S}_{8}$ in DMSO can be up to $1 \mathrm{M}$ (Supplementary Fig. 5a), ensuring a high volumetric energy density ${ }^{7}$. A prototype $\mathrm{Na}_{2} \mathrm{~S}_{8}|\mathrm{BASE}| \mathrm{Na}-\mathrm{BP}-\mathrm{DME}$ cell was assembled with a BASE tube separating the liquid anode (inside the tube) and liquid cathode, and the carbon felt and nickel foam were used as the current collectors, respectively, (Supplementary Fig. 6a,b). The cell was first discharged to $1.8 \mathrm{~V}$ and then charged to $2.5 \mathrm{~V}$ at a current density of $300 \mathrm{~mA} \mathrm{~g}^{-1}$ (that is, $1 \mathrm{C}$ rate). After several cycles between 1.8 and $2.5 \mathrm{~V}$, the cutoff voltage was set between 1.2 and $2.5 \mathrm{~V}$. Typical discharge and charge profiles are presented in Fig. 3a. The discharge profile displays three different regions, which corresponds to S-to- $\mathrm{Na}_{2} \mathrm{~S}_{8}$ (I), $\mathrm{Na}_{2} \mathrm{~S}_{8}$-to- $\mathrm{Na}_{2} \mathrm{~S}_{4}$ (II) and $\mathrm{Na}_{2} \mathrm{~S}_{4}$-to- $\mathrm{Na}_{2} \mathrm{~S}_{3}$ (III), respectively. 
a

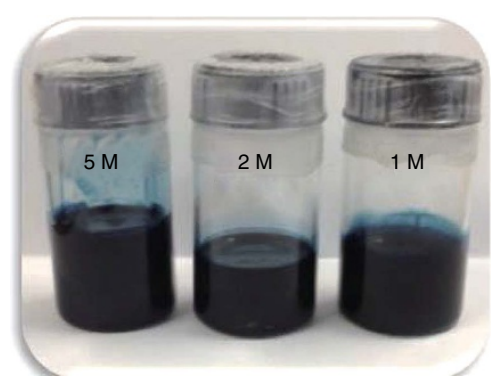

b

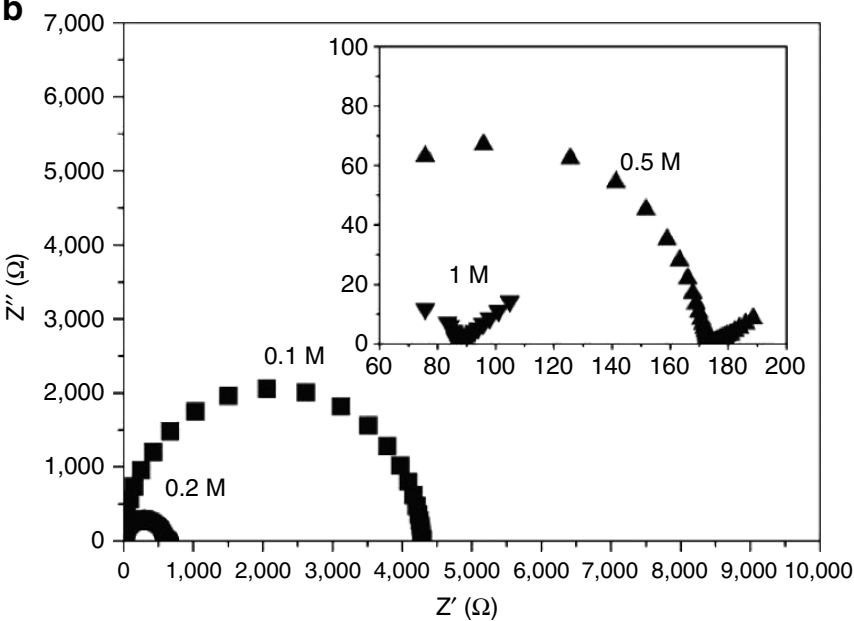

C

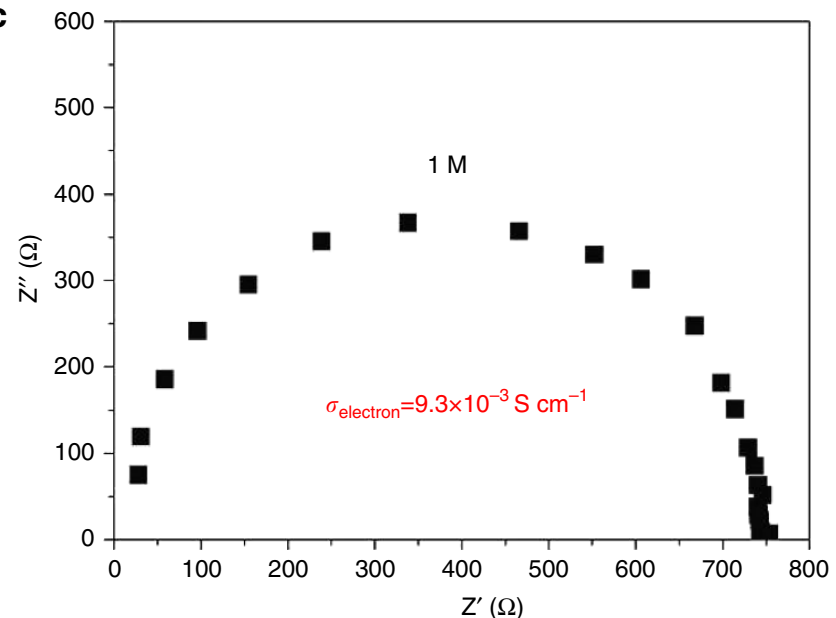

$Z^{\prime}(\Omega)$

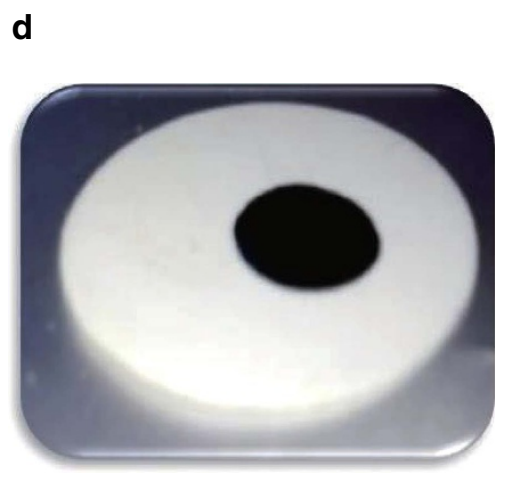

Figure 1 | Physical properties of Na-BP-DME liquid solution. (a) Photograph of Na-BP-DME solution with different concentrations. (b) Electrochemical impedance spectra of Na-BP-DME solution with different concentrations (cell constant: $K=1.05$ ). (c) Electrochemical impedance spectrum of $1 \mathrm{M}$ Na-BP-DME measured with $\mathrm{Na}^{+}$ion blocking cell (cell constant: $K=7.0$ ). (d) Wetting behaviour of liquid Na-BP-DME drops on $\mathrm{Na}-\beta^{\prime \prime}-\mathrm{Al}_{2} \mathrm{O}_{3}$ solid electrolyte.
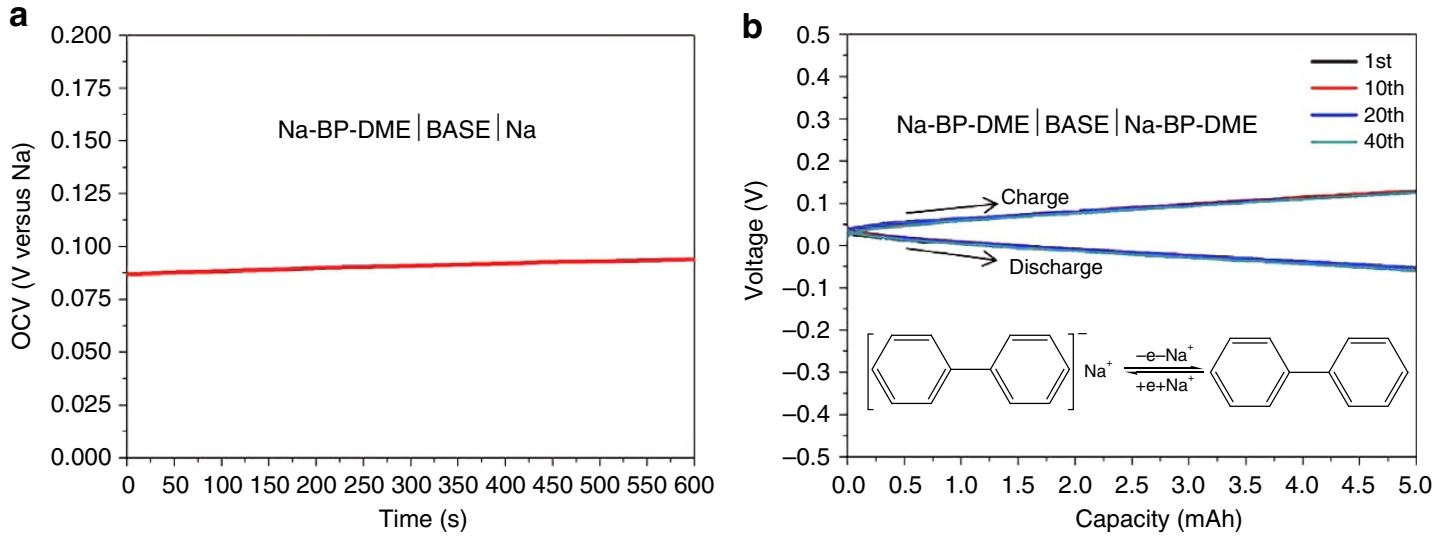

Figure 2 | Electrochemical properties of Na-BP-DME liquid solution. (a) The open circuit voltage of Na-BP-DME|BASE|Na cell. (b) Cycle performance of Na-BP-DME|BASE|Na-BP-DME symmetric cell.

The high reversibility of those three processes is manifested by over 300 cycles with capacity retention of $95 \%$ (Fig. 3b). Although the cycling stability is good, the round-trip efficiency is only $90 \%$ in the initial cycles and stabilizes at $87 \%$, which is mainly due to the sluggish kinetics ${ }^{9}$ and the limited solubility of $\mathrm{Na}_{2} \mathrm{~S}_{3}$ in DMSO (Supplementary Fig. 5b). To further increase the round-trip efficiency, the cutoff voltage is set between 1.8 and $2.5 \mathrm{~V}$ (Fig. 3c). The electrochemical reactions at the anode and cathode are:
Anode:

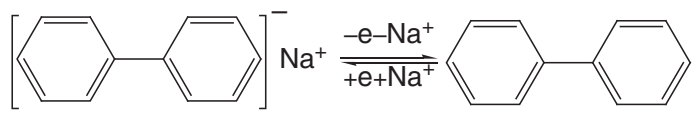

Cathode:

$$
\mathrm{S}_{8}{ }^{2-} \longrightarrow \mathrm{S}_{4}{ }^{2-} \rightleftharpoons \mathrm{S}_{8}
$$



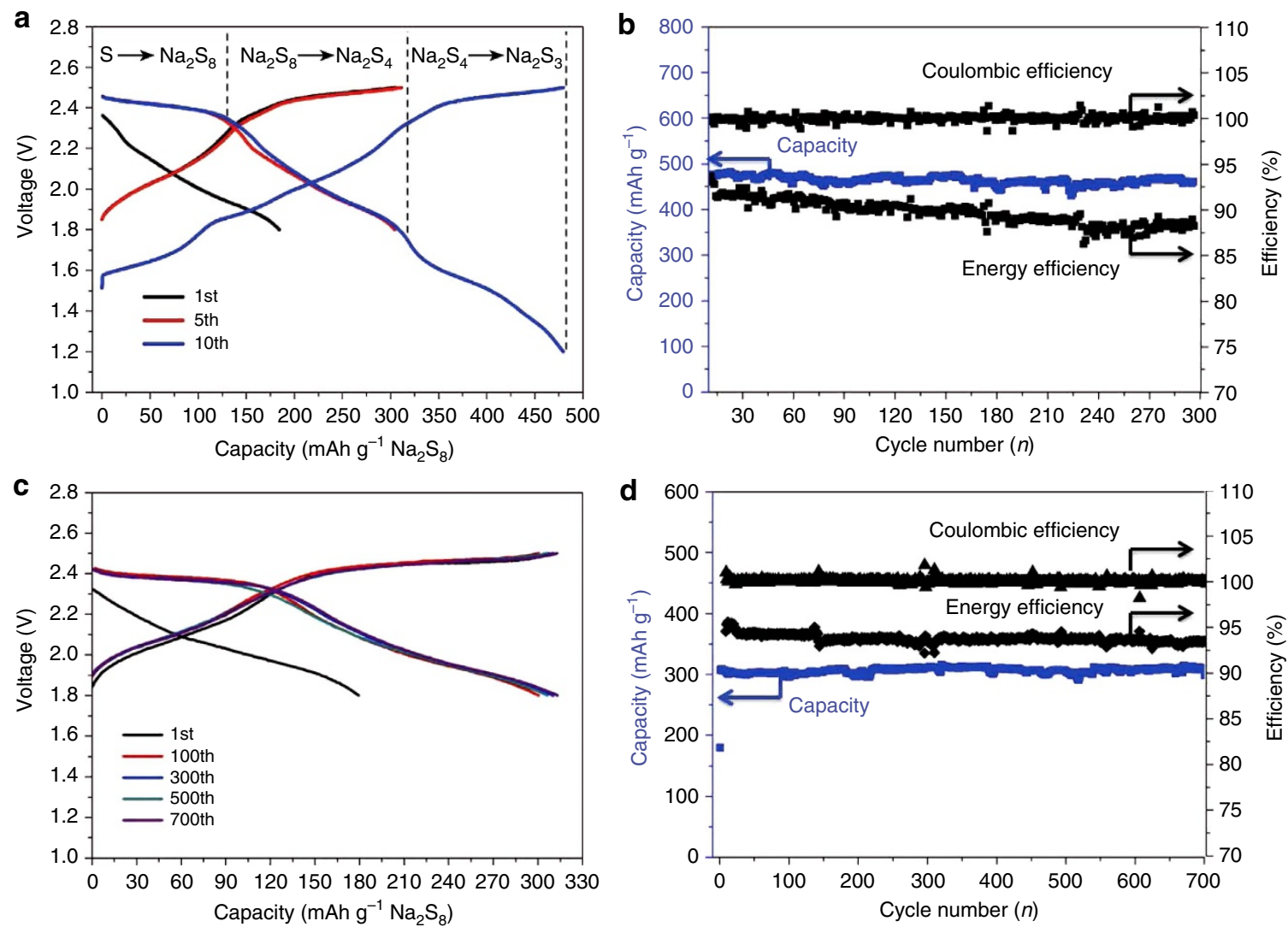

Figure 3 | Electrochemical performance of $\mathbf{N a}_{\mathbf{2}} \mathbf{S}_{\mathbf{8}}|\mathbf{B A S E}| \mathbf{N a}-\mathbf{B P}-\mathbf{D M E}(\mathbf{1} \mathbf{M})$ cells. (a) Galvanostatic discharge and charge profiles of $\mathrm{Na}_{2} \mathrm{~S}_{8}|\mathrm{BASE}|$ $\mathrm{Na}-\mathrm{BP}-\mathrm{DME}$ cells cycled between 1.2 and $2.5 \mathrm{~V}$. (b) Cycle stability of $\mathrm{Na}_{2} \mathrm{~S}_{8}|\mathrm{BASE}| \mathrm{Na}$-BP-DME cells in the voltage range of $1.2-2.5 \mathrm{~V}$ under a constant current density of $300 \mathrm{mAg}^{-1}$. (c) Galvanostatic discharge and charge profiles of $\mathrm{Na}_{2} \mathrm{~S}_{8}|\mathrm{BASE}| \mathrm{Na}-\mathrm{BP}-\mathrm{DME}$ cells cycled between 1.8 and $2.5 \mathrm{~V}$. (d) Cycle performance of $\mathrm{Na}_{2} \mathrm{~S}_{8}|\mathrm{BASE}| \mathrm{Na}-\mathrm{BP}-\mathrm{DME}$ cells in the voltage range of $1.8-2.5 \mathrm{~V}$ under a constant current densities of $300 \mathrm{mAg}^{-1}$. These cells were assembled with $\mathrm{Na}-\beta^{\prime \prime}-\mathrm{Al}_{2} \mathrm{O}_{3}$ tube ( $\mathrm{L} 5 \mathrm{O} \times \mathrm{OD} 13 \mathrm{~mm}, 1 \mathrm{~mm}$ thickness).

It can be seen that the reversible capacity in this voltage range is $310 \mathrm{mAh} \mathrm{g}^{-1}$, which corresponds to the formation of $\mathrm{Na}_{2} \mathrm{~S}_{4}$ that can be fully dissolved in DMSO (Supplementary Fig. $5 \mathrm{c}$ ). It is noteworthy that the cell exhibits outstanding cycling performance with no measureable capacity loss after 700 cycles (Fig. 3d), suggesting superior stability of both sulfur cathodes and Na-BPDME liquid anodes. The Coulombic efficiency is close to $100 \%$, resulting from the use of a solid electrolyte, which blocks the diffusion of polysulfide to the anode side. Most importantly, the round-trip efficiency remains at $94 \%$ after 700 cycles. The volumetric and gravimetric energy densities of the system with this liquid anode and polysulfide cathode were calculated to be $94 \mathrm{Whl}^{-1}$ and $80 \mathrm{Wh} \mathrm{kg}^{-1}$, respectively, (Supplementary Tables 2 and 3) (note that the $5 \mathrm{M}$ Na-BP-DME system displays the very similar discharge/charge behaviour to that of $1 \mathrm{M}$ Na-BP-DME system as shown in Supplementary Fig. 7 under the same conditions.). The cost of raw materials in this system is only $11.8 \$ \mathrm{kWh}^{-1}$ (Supplementary Table 4, without considering the cost of BASE.). These values are superior to conventional redox flow batteries ${ }^{25}$ and higher than recently reported new battery systems ${ }^{26-30}$ (Supplementary Table 5). Note that, in principle, we can even add $\mathrm{Na}$ metal into this saturated $\mathrm{Na}-\mathrm{BP}-\mathrm{DME}$ solution to achieve much higher energy density $\left(201 \mathrm{Whl}^{-1}\right.$ and $149 \mathrm{Wh} \mathrm{kg}^{-1}$ (Supplementary Table 3)). In this case, the liquid can function as an interfacial wetting agent between solid electrolyte and $\mathrm{Na}$ metal (Supplementary Fig. 6c). The electrochemical performance of $\mathrm{Na}$ metal in Na-saturated BPDME liquid hybrid electrode is shown in Supplementary Fig. 8. It can be seen that this hybrid electrode displays a high reversibility and stability.

In this alkali metal solution, other ether solvents can also be used. The conductivities of all the tested systems are in the order of $10^{-3} \mathrm{~S} \mathrm{~cm}^{-1}$ (Supplementary Fig. 9). In particular, the electrochemical performance of $\mathrm{Na}_{2} \mathrm{~S}_{8}|\mathrm{BASE}| \mathrm{Na}-\mathrm{BP}-\mathrm{TEGDME}$ cell was demonstrated to be similar to that of Na-BP-DME system (Fig. 4a,b). The rate performance of $\mathrm{Na}_{2} \mathrm{~S}_{8}|\mathrm{BASE}| \mathrm{Na}-\mathrm{BP}$ TEGDME cell is shown in Fig. $4 \mathrm{c}$ and it can be seen that the capacity retention of $63 \%$ at $880 \mathrm{~mA} \mathrm{~g}^{-1}$ can be achieved without optimization. Furthermore, the cell was cycled at $1,100 \mathrm{mAg}^{-1}$ for 3,500 cycles without any capacity decay (Fig. 4d).

Another noteworthy property of this liquid anode is the high degree of safety. It is well known that $\mathrm{Na}$ metal reacts drastically with water, posing a serious safety hazard. Here we checked the reaction of Na-BP-DME liquid anode by adding water drop by drop into the Na-BP-DME solution. Interestingly, the reaction is much milder than that of $\mathrm{Na}$ metal and no fire was observed during the whole process (Supplementary Fig. 10a and Supplementary Videos 3 and 4). This is because the reaction follows as refs 15-17:

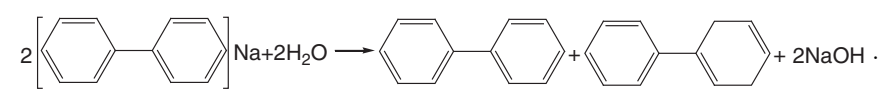

Unlike Na metal reacting with water (Supplementary Video 5), no hydrogen $\left(\mathrm{H}_{2}\right)$ is generated during the reaction. Furthermore, no 

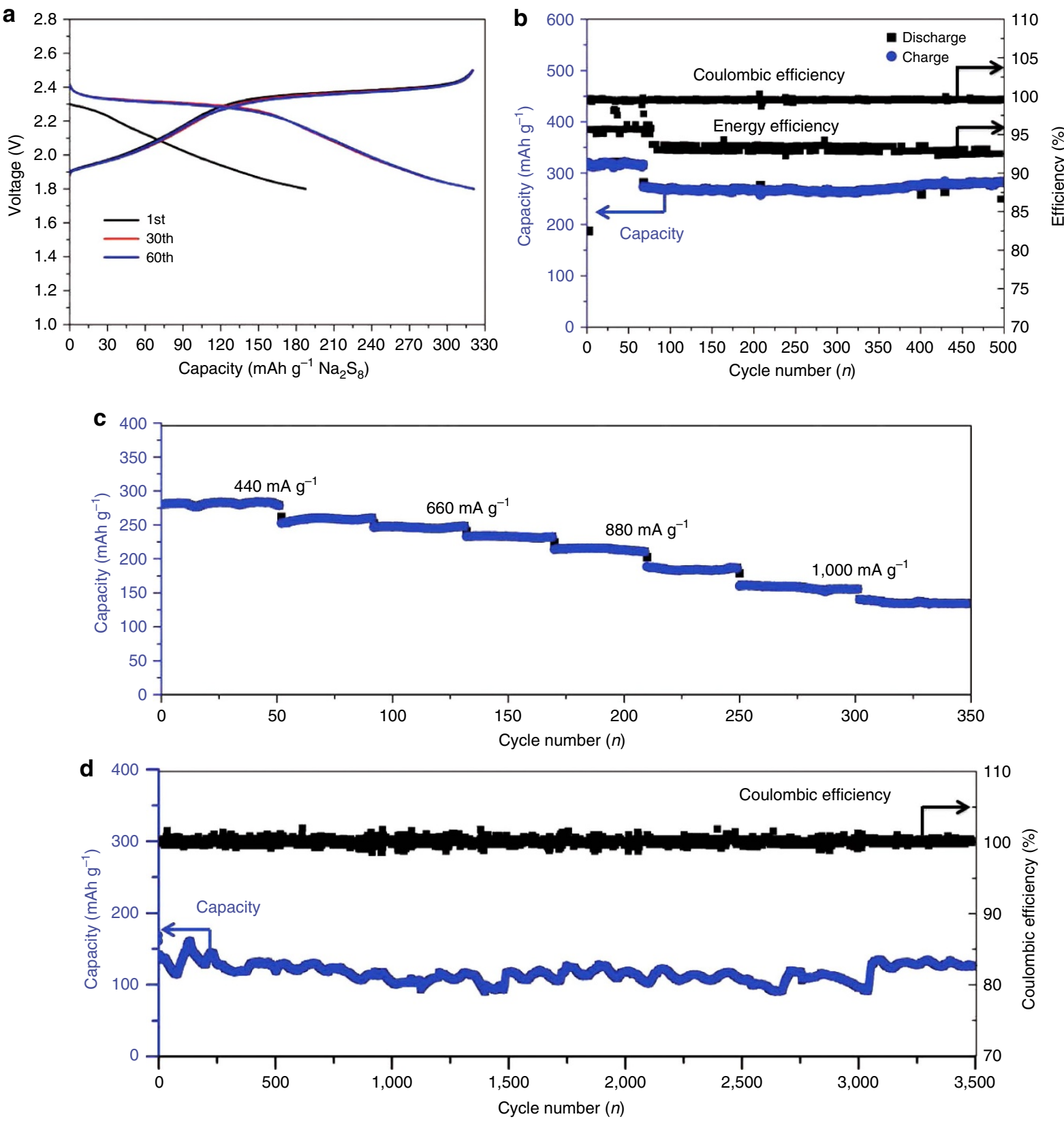

Figure 4 | Electrochemical performance of $\mathbf{N a}_{\mathbf{2}} \mathbf{S}_{\mathbf{8}}|\mathbf{B A S E}| \mathbf{N a}-\mathbf{B P}-\mathbf{T E G D M E}(\mathbf{1} \mathbf{M})$ cells. (a) Galvanostatic discharge and charge profiles of $\mathrm{Na}_{2} \mathrm{~S}_{8}|\mathrm{BASE}|$ $\mathrm{Na}-\mathrm{BP}-\mathrm{TEGDME}$ cells cycled between 1.8 and $2.5 \mathrm{~V}$. (b) Cycle stability of $\mathrm{Na}_{2} \mathrm{~S}_{8}|\mathrm{BASE}| \mathrm{Na}-\mathrm{BP}-\mathrm{TEGDME}$ cells in the voltage range of $1.8-2.5 \mathrm{~V}$ under a constant current density of 330 and $440 \mathrm{mAg}^{-1}$. (c) Rate performance of $\mathrm{Na}_{2} \mathrm{~S}_{8}|\mathrm{BASE}| \mathrm{Na}-\mathrm{BP}-\mathrm{TEGDME}$ cells cycled between 1.8 and $2.5 \mathrm{~V}$ at different current density. (d) Long cycle stability of $\mathrm{Na}_{2} \mathrm{~S}_{8}|\mathrm{BASE}| \mathrm{Na}-\mathrm{BP}-\mathrm{TEGDME}$ cells in the voltage range of $1.8-2.5 \mathrm{~V}$ under constant current densities of $1,100 \mathrm{mAg}^{-1}$. These cells were assembled with $\mathrm{Na}-\beta^{\prime \prime}-\mathrm{Al}_{2} \mathrm{O}_{3}$ tube $(\mathrm{L} 50 \times \mathrm{OD} 13 \mathrm{~mm}, 1 \mathrm{~mm}$ thickness).

drastic reaction occurred when adding $\mathrm{Na}_{2} \mathrm{~S}_{8}$ solution into the Na-BP-DME solution drop by drop (Supplementary Fig. 10c and Supplementary Video 6). The change of temperature for both reactions was also recorded and shown in Supplementary Fig. 10b,d. It can be seen that the increase of temperature cannot exceed $20^{\circ} \mathrm{C}$ when Na-BP-DME reacts with water, while the temperature change is less than $10^{\circ} \mathrm{C}$ for the reaction of $\mathrm{Na}$-BP-DME with $\mathrm{Na}_{2} \mathrm{~S}_{8}$ solution. These peculiar properties make the room temperature $\mathrm{Na}_{2} \mathrm{~S}_{8}|\mathrm{BASE}| \mathrm{Na}$-BP-DME battery intrinsically safer than the state-of-the-art high-temperature $\mathrm{Na}-\mathrm{S}$ batteries, which is a very important advantage by using this system for large-scale applications.

\section{Discussion}

In conclusion, we have demonstrated the use of a class of Na-BPEther liquid anode in room temperature rechargeable sodium beta-alumina batteries. The liquid anodes hold some distinct advantages over the current alkali metal-based technologies. First, this liquid anode has high electronic/ionic conductivity with superior reversibility and stability of $\mathrm{Na}$ removal/uptake at a low redox potential. It can wet the solid electrolyte well, and is dendrite-free and SEI-free with low cost and high safety. Second, our strategy is tunable as different alkali metals, aromatic hydrocarbons or ether solvents can be chosen to tune the physical and electrochemical properties ${ }^{13,14}$. Third, sulfur cathodes, and 
other high soluble ${ }^{30}$ or slurry cathodes can also be used ${ }^{31}$. Finally, the cell can be designed as either a cylindrical/planar cell or a redox flow cell with a separation of energy and power as shown in Supplementary Fig. 11 (note that the preliminary electrochemical performance of the redox flow battery at this stage was shown in Supplementary Figs 12 and 13. We believe that the performance can be further improved by optimizing the system and engineering the cell structure, for instance, using new catholyte system with higher energy density, a thinner $\mathrm{Na}-\beta^{\prime \prime}-\mathrm{Al}_{2} \mathrm{O}_{3}$ electrolyte or new electrolyte with higher ionic conductivity, and a highly porous current collector). This class of liquid anode could open up an exciting route for long-life, cost-effective and safe rechargeable batteries that potentially meet the requirements for grid-scale electrical energy storage.

\section{Methods}

Preparation of Na-BP-DME liquid anodes. A dark green liquid Na-BP-DME was prepared by dissolving sodium metal (Aldrich, 99.5\%) into biphenyl (Aldrich, 99\%) and DME (BASF) solution in glove box filled with Argon. In a typical procedure, $1.54 \mathrm{~g}$ biphenyl was dissolved into $10 \mathrm{ml}$ DME solvent to make a $1 \mathrm{M}$ BP-DME solution and then $0.23 \mathrm{~g}$ sodium metal was dissolved into this solution to form a $1 \mathrm{M}$ Na-BP-DME solution. It should be noted that the molar ratio of Na:BP was fixed at 1:1. Different concentrations of Na-BP-DME or Na-BP-TEGDME liquid solutions were prepared by the same procedure.

Electronic and $\mathrm{Na}^{+}$ionic conductivity measurement. Total conductivity was measured by the electrochemical impedance spectrum, which was carried out on a Zahner IM6. The test frequency ranges from $100 \mathrm{mHz}$ to $6 \mathrm{MHz}$. The conductance cell is Rosull DJS-1(cell constant: $K=1.05$ ) as displayed in Supplementary Fig. 2a. $\mathrm{A} \mathrm{Na}^{+}$ion blocking cell which was illustrated in Supplementary Fig. $2 \mathrm{~b}$ was used to measure the electronic conductivity of Na-BP-DME liquid solution (cell constant: $K=7.0$ ). The $\mathrm{Na}^{+}$ion can be blocked by the copper foil (thickness: $8 \mu \mathrm{m}$ ) in the ion blocking cell, but electron can pass through the whole cell during measurement.

Preparation of $\mathbf{N a}_{2} \mathbf{S}_{\mathbf{8}}$-DMSO liquid cathodes. The $\mathrm{Na}_{2} \mathrm{~S}_{8}$ liquid cathode was prepared in glove box filled with Argon. Typically, $0.78 \mathrm{~g} \mathrm{Na}_{2} \mathrm{~S}$ (Aldrich, 98\%), $2.24 \mathrm{~g} \mathrm{~S}$ (Aldrich, 99\%) and $0.85 \mathrm{~g} \mathrm{CF}_{3} \mathrm{SO}_{3} \mathrm{Na}$ (Aldrich, 99.5\%) were dissolved into $10 \mathrm{ml}$ DMSO solvent to form a $1 \mathrm{M} \mathrm{Na}_{2} \mathrm{~S}_{8}$-DMSO solution (note that $\mathrm{NaSO}_{3} \mathrm{CF}_{3}$ was used as the supporting electrolyte).

Cell construction and electrochemical tests. Single cells of $\mathrm{Na}_{2} \mathrm{~S}_{8}|\mathrm{BASE}|$ $\mathrm{Na}-\mathrm{BP}-\mathrm{DME}$ were assembled according to a high temperature $\mathrm{Na}-\mathrm{S}$ battery. In detail, $1 \mathrm{ml} 1 \mathrm{M}$ Na-BP-DME solution was injected into $\mathrm{Na}-\beta^{\prime \prime}-\mathrm{Al}_{2} \mathrm{O}_{3}$ tube $(\mathrm{L} 50 \times \mathrm{OD} 13 \mathrm{~mm}, 1 \mathrm{~mm}$ in thickness, Ionotec Company, ionic conductivity at room temperature is $1.67 \times 10^{-3} \mathrm{~S} \mathrm{~cm}^{-1}$ ) and nickel foam was plugged into this solution as a current collector. Then, $\mathrm{Na}_{2} \mathrm{~S}_{8}$-DMSO liquid cathode was poured into stainless steel cylinder housing $(\mathrm{L} 60 \times \mathrm{OD} 18 \mathrm{~mm})$ and carbon felt was used as a current collector. Finally, the $\mathrm{Na}-\beta^{\prime \prime}-\mathrm{Al}_{2} \mathrm{O}_{3}$ tube filled with $\mathrm{Na}-\mathrm{BP}-\mathrm{DME}$ solution was inserted into the stainless steel cylinder filled with $\mathrm{Na}_{2} \mathrm{~S}_{8}$-DMSO liquid cathode. Electrochemical performance was tested with BT-2000 Arbin Battery Testing system at room temperature. The cells were discharged and charged in the voltage ranges of $1.2-2.5 \mathrm{~V}$ and $1.8-2.5 \mathrm{~V}$ at a constant current mode.

Symmetric cell of Na-BP-DME|BASE|Na-BP-DME was assembled with $1 \mathrm{M}$ $\mathrm{Na}-\mathrm{BP}-\mathrm{DME}$ as cathode and anode. In detail, $0.43 \mathrm{ml} 1 \mathrm{M} \mathrm{Na}-\mathrm{BP}-\mathrm{DME}$ solution was injected into $\mathrm{Na}-\beta^{\prime \prime}-\mathrm{Al}_{2} \mathrm{O}_{3}$ tube and stainless steel cylinder, nickel foam was plugged into this solution as a current collector. Electrochemical performance was tested with BT-2000 Arbin Battery Testing system at room temperature with a limited capacity of $5 \mathrm{mAh}$. The same symmetric cell with excess $\mathrm{Na}$ metal soaked in $\mathrm{Na}$-BP-DME was assembled as the same procedure, the only difference is that excess $\mathrm{Na}$ metal piece was added into the Na-BP-DME cathode and anode (note that the concentration of BP in DME was $1 \mathrm{M}$ ). Electrochemical performance was tested with BT-2000 Arbin Battery Testing system at room temperature with a limited capacity of $6 \mathrm{mAh}$.

Reaction temperature tests. The changes of temperature for reactions of $\mathrm{Na}-\mathrm{BP}-\mathrm{DME}$ with water and $\mathrm{Na}_{2} \mathrm{~S}_{8}$ cathode were measured with highly precise temperature sensor JULABO-PHYSICS (Julabo Company). In detail, the temperature sensor was inserted into the inside drop by drop added $1 \mathrm{ml}$ $\mathrm{Na}-\mathrm{BP}-\mathrm{DME}$ and then $1 \mathrm{ml}$ water. Similarly, the temperature sensor was also inserted into the inside dropwise added $40 \mathrm{ml} \mathrm{Na-BP-DME}$ and then $10 \mathrm{ml}$ $\mathrm{Na}_{2} \mathrm{~S}_{8}$-DMSO
Data availability. The authors declare that the data supporting the findings of this study are available within the article and its Supplementary Information Files. All other relevant data supporting the findings of this study are available from the corresponding author on request.

\section{References}

1. Armand, M. \& Tarascon, J.-M. Building better batteries. Nature 451, 652-657 (2008).

2. Dunn, B., Kamath, H. \& Tarascon, J.-M. Electrical energy storage for the grid: a battery of choices. Science 334, 928-935 (2011).

3. Yang, Z. et al. Electrochemical energy storage for green grid. Chem. Rev. 111, 3577-3613 (2011).

4. Bruce, P. G., Freunberger, S. A., Hardwick, L. J. \& Tarascon, J.-M. Li-O $\mathrm{O}_{2}$ and Li-S batteries with high energy storage. Nat. Mater. 11, 19-29 (2012).

5. Huang, Q. \& Wang, Q. Next-generation, high-energy-density redox flow batteries. ChemPlusChem. 80, 312-322 (2015).

6. Lu, Y., Goodenough, J. B. \& Kim, Y. Aqueous cathode for next-generation alkali-ion batteries. J. Am. Chem. Soc. 133, 5756-5759 (2011).

7. Yang, Y., Zheng, G. \& Cui, Y. A membrane-free lithium/polysulfide semiliquid battery for large-scale energy storage. Energy Environ. Sci. 6, 1552-1558 (2013).

8. Yu, X. \& Manthiram, A. Room-temperature sodium-sulfur batteries with liquid-phase sodium polysulfide catholytes and binder-free multiwall carbon nanotube fabric electrodes. J. Phys. Chem. C 118, 22952-22959 (2014).

9. Manthiram, A. \& Yu, X. Ambient temperature sodium-sulfur batteries. Small 11, 2108-2114 (2015).

10. Yu, X. \& Manthiram, A. Ambient-temperature sodium-sulfur batteries with a sodiated nafion membrane and a carbon nanofiber-activated carbon composite electrode. Adv. Energy Mater. 5, 1500350 (2015).

11. Kohl, M. et al. Hard carbon anodes and novel electrolytes for long-cycle-life room temperature sodium-sulfur full cell batteries. Adv. Energy Mater. 6, 1502185 (2016).

12. Kim, I. et al. A singular flexible cathode for room temperature sodium/sulfur battery. J. Power Sources 307, 31-37 (2016).

13. Hueso, K. B., Armand, M. \& Rojo, T. High temperature sodium batteries: status, challenges and future trends. Energy Environ. Sci. 6, 734-749 (2013)

14. Wen, Z., Hu, Y., Wu, X., Han, J. \& Gu, Z. Main challenges for high performance NAS battery: materials and interfaces. Adv. Funct. Mater. 23, 1005-1018 (2013).

15. Lu, X. et al. The effects of temperature on the electrochemical performance of sodium-nickel chloride batteries. J. Power Sources 215, 288-295 (2012).

16. Lu, X. et al. Liquid-metal electrode to enable ultra-low temperature sodiumbeta alumina batteries for renewable energy storage. Nat. Commun. 5, 4578 (2014).

17. Wang, K. et al. Lithium-antimony-lead liquid metal battery for grid-level energy storage. Nature 514, 348-350 (2014).

18. Kim, S. W., Seo, D. H., Ma, X., Ceder, G. \& Kang, K. Electrode materials for rechargeable sodium-ion batteries: potential alternatives to current lithium-ion batteries. Adv. Energy Mater. 2, 710-721 (2012).

19. Palomares, V., Casas-Cabanas, M., Castillo-Martínez, E., Han, M. H. \& Rojo, T Update on Na-based battery materials. A growing research path. Energy Environ. Sci. 6, 2312-2337 (2013).

20. Scott, N., Walker, J. \& Hansley, V. Sodium naphthalene. i. a new method for the preparation of addition compounds of alkali metals and polycyclic aromatic hydrocarbons. J. Am. Chem. Soc. 58, 2442-2444 (1936).

21. Freeman, P. K. \& Hutchinson, L. L. Alkyllithium reagents from alkyl halides and lithium radical anions. J. Org. Chem. 45, 1924-1930 (1980).

22. Connelly, N. G. \& Geiger, W. E. Chemical redox agents for organometallic chemistry. Chem. Rev. 96, 877-910 (1996).

23. Holy, N. Reactions of the radical anions and dianions of aromatic hydrocarbons. Chem. Rev. 74, 243-277 (1974).

24. Garst, J. F. Electron transfer, naphthalene radical anion, and alkyl halides. Acc. Chem. Res. 4, 400-406 (1971).

25. Li, L. et al. A stable vanadium redox-flow battery with high energy density for large-scale energy storage. Adv. Energy Mater. 1, 394-400 (2011).

26. Huskinson, B. et al. A metal-free organic-inorganic aqueous flow battery. Nature 505, 195-198 (2014).

27. Janoschka, T. et al. An aqueous, polymer-based redox-flow battery using non-corrosive, safe, and low-cost materials. Nature 527, 78-81 (2015).

28. Lin, K. et al. Alkaline quinone flow battery. Science 349, 1529-1532 (2015).

29. Huang, J. et al. Liquid catholyte molecules for nonaqueous redox flow batteries. Adv. Energy Mater. 5, 1401782 (2015).

30. Cosimbescu, T. L. et al. TEMPO-based catholyte for high-energy density nonaqueous redox flow batteries. Adv. Mater. 26, 7649-7653 (2014).

31. Duduta, M. et al. Semi-solid lithium rechargeable flow battery. Adv. Energy Mater. 1, 511-516 (2011). 


\section{Acknowledgements}

This work was supported by funding from '973' Projects (2014CB932300), the NSFC $(51222210,51472268,11234013$ and 51421002) and One Hundred Talent Project of the Chinese Academy of Sciences.

\section{Author contributions}

Y.-S.H. designed this work; J.Y. carried out the synthesis and electrochemical experiments; F.P. and Q.W. evaluated the electrochemical performance of flow batteries; Y.-S.H. wrote the paper; all the authors participated in analysis of the experimental data and discussions of the results as well as preparing the paper.

\section{Additional information}

Supplementary Information accompanies this paper at http://www.nature.com/ naturecommunications

Competing financial interests: The authors declare no competing financial interests.
Reprints and permission information is available online at http://npg.nature.com/ reprintsandpermissions/

How to cite this article: Yu, J. et al. A class of liquid anode for rechargeable batteries with ultralong cycle life. Nat. Commun. 8, 14629 doi: 10.1038/ncomms14629 (2017)

Publisher's note: Springer Nature remains neutral with regard to jurisdictional claims in published maps and institutional affiliations.

\section{(c) (1)}

This work is licensed under a Creative Commons Attribution 4.0 International License. The images or other third party material in this article are included in the article's Creative Commons license, unless indicated otherwise in the credit line; if the material is not included under the Creative Commons license, users will need to obtain permission from the license holder to reproduce the material. To view a copy of this license, visit http://creativecommons.org/licenses/by/4.0/

(C) The Author(s) 2017 